\title{
NOVO CARF E PLANEJAMENTO TRIBUTÁRIO COM OPERAÇÕES SOCIETÁRIAS
}

\author{
NEW CARF AND TAX PLANNING WITH CORPORATE OPERATIONS
}

Recebido em 11.08.2018. Aprovado em 05.06.2019 Avaliado pelo sistema double blind review DOI: https://doi.org/10.12712/rpca.v13i2.13181

\section{Antonio Lopo Martinez}

antoniolopomartinez@gmail.com

Programa de Doutorado em Direito/Universidade de Coimbra - Coimbra, Portugal

ORCID: https://orcid.org/0000-0001-9624-7646

\section{João Pedro Earl Galvêas Oliveira}

joaopedroearlgalveasoliveira@hotmail.com

Programa de Mestrado Profissional em Contabilidade/Fucape Business School - Vitoria, Es, Brasil

ORCID: https://orcid.org/0000-0002-6813-043X

\section{Resumo}

Quais são os critérios de validade relevantes nos julgamentos de um planejamento tributário no Novo CARF? A pesquisa coletou Acórdãos proferidos entre dezembro de 2015 a dezembro de 2017, envolvendo reestruturação societária, utilizando o método "normative systems" e regressões lineares, verificaram-se a significância de critérios de validade. Os resultados reiteram a importância do proposito negocial e da ausência de simulação, mas destacam características procedimentais que influenciam no resultado de um julgamento. Quem fez o voto vencedor condutor do Acórdão, se houve o voto de qualidade e o valor do crédito tributário, influenciam na validação ou invalidação do planejamento tributário.

Palavras-chave: Planejamento tributário. Critérios de validade. Operações societárias; CARF.

\begin{abstract}
What are the relevant validity criteria in the judgments of a tax plan in the new CARF? The research collected judgments delivered between December 2015 to December 2017, which involved corporate restructuring, using the "normative systems" method and linear regressions, verifies the significance of validity criteria. The results reiterate the importance of the business purpose and the absence of simulation, but also highlight procedural characteristics that have significance in the outcome of a trial. Who makes the winning vote, if there was the quality vote and the value of the tax credit, influence the validation or invalidation of tax planning.
\end{abstract}

Keywords: Tax planning. Validity criteria. Corporate operations; CARF 


\section{Introdução}

A presente pesquisa teve por objetivo analisar se o Novo Conselho Administrativo de Recursos Federais (Novo CARF) mantém os critérios utilizados para definir a validade ou não de operações societárias típicas que têm por intento diminuir, postergar ou evitar o pagamento de tributos, após à Operação Zelotes, considerando as respostas encontradas por Schoueri et. al. (2010) e Martinez e Coelho (2016). Adicionalmente, ineditamente na literatura, procurou analisar questões referentes a particularidades do julgamento e sua relação com os resultados, tais como a decisão por voto de qualidade, quem foi o voto vencedor, quem foi o relator, o placar da votação e o valor de crédito tributário envolvido, que poderiam influenciar no resultado.

Importante registrar que à Operação Zelotes tem como intuito investigar um esquema de corrupção dentro do CARF que, por sua vez, é um órgão colegiado integrante do Ministério da Fazenda responsável por julgar os recursos administrativos (NOBRE JÚNIOR; PIMENTEL, 2016).

O interesse na pesquisa decorre da atual falta de segurança para a tomada de decisões no que se refere ao planejamento tributário, pois, de acordo com Quintino e Macei (2015), atualmente o CARF realiza uma análise da substância do negócio jurídico, e não somente da forma, como anteriormente ocorria. Dessa feita é necessário que o contribuinte esteja, caso confrontado pelo Estado, apto a apresentar justificativas para a realização do negócio jurídico, sob pena de invalidação do planejamento tributário (QUINTINO;MACEI, 2015).

É importante enfatizar que a literatura internacional, bem como nacional, vêm debruçando-se sobre o tema de planejamento tributário, fato este que torna o assunto de grande relevo (RANDOLPH; SEIDA, 2007; SCHOUERI, 2010; COELHO, 2013; GRAHAM et al., 2014). Além disso, o tema ora proposto já vem sendo analisado há algum tempo, mas escassos estudos são empíricos (DYRENG; HANLON; MAYDEW, 2010).

Como ponto de partida, utilizou-se a metodologia proposta por Schoueri et. al. (2010). Essa metodologia, exposta por Alchourrón e Bulygin (1975), é conhecida como "normative systems". No presente estudo buscou-se ir diretamente para as características fáticas dos casos com base na fundamentação e conclusão dos julgadores.

O procedimento passa por analisar os acórdãos proferidos pelo CARF e, posteriormente, verificar se houve a aplicação ou não das propriedades e controles. Essas propriedades consistem-se de perguntas a serem respondidas de forma positiva ou negativa, considerando-se que nos casos positivos a propriedade foi observada para julgamento e, caso negativa, que ela não foi considerada, sendo também possível a não manifestação.

Os Acórdãos foram coletados no site do CARF, focando nos acórdãos posteriores à Operação Zelotes e reestruturação do Conselho Administrativo de Recursos Federais, portanto, do período de dezembro de 2015 a dezembro de 2017. Todos os atos de seus julgamentos são públicos, portanto, não houve grande impeditivo para acessar-se às informações necessárias (COELHO, 2013). Posteriormente a essa análise foi utilizado um modelo de regressão linear que possibilitou chegar aos resultados expostos nos tópicos a seguir.

O restante do trabalho está estruturado em quatro tópicos. Primeiro que tratará acerca do referencial teórico e que também realizará uma revisão da literatura, no qual ainda serão apresentadas as hipóteses de pesquisa. Segundo em que apresenta a metodologia de pesquisa e discorre acerca dos fatores a ela inerentes, tais como método, observações, análise de dados, dentre outros. Terceiro no qual se analisam os acórdãos encontrados e expõem-se os resultados observados. Quarto e último realizam-se as considerações finais acerca do presente estudo. 


\section{Teoria Utilizada}

A sustentação teórica do presente estudo advém de dois trabalhos anteriores que enfrentaram a mesma temática em momentos temporais distintos. O primeiro, de Schoueri et. al. (2010), apreciando os Conselhos de Contribuintes e o segundo de Martinez e Coelho (2016), apreciando o CARF. Ambos os trabalhos concluem que é condição relevante, para que o planejamento tributário seja validado, que o mesmo tenha propósitos negociais, ou seja, que não tenha sido realizado meramente para o não pagamento de tributos.

Note-se que os achados identificados por Martinez e Coelho (2016) não foram tão robustos quanto aqueles encontrados por Schoueri et. al. (2010), logo, havia a necessidade de se realizar uma nova investigação no intuito de confirmar as propriedades: P1: Os fatos foram considerados existentes tais como narrados pelo contribuinte? ; P2: Foram observadas normas cogentes não tributárias?; P3: A operação teve outros propósitos não tributários?; P4: Houve adequado intervalo temporal entre as operações? e P5: As partes envolvidas eram independentes? se mantém. Bem como, se há fatores não expressos nos julgamentos e que possuem relação com o resultado, tais como: voto de qualidade (C1), voto vencedor $(\mathrm{C} 2)$, quem foi o relator $(\mathrm{C} 3)$, placar da votação $(\mathrm{C} 4)$ e o valor de crédito tributário na lide (C5).

Em função da Operação Zelotes, foram realizadas alterações na estrutura do Conselho Administrativo de Recursos Federais (CARF), resultando-se na diminuição do número de conselheiros; dedicação exclusiva as atividades do CARF; redução do mandato dos conselheiros; alteração na forma de escolha; criação de conselho de ética dentro do CARF; dentre outras no intuito de atingir uma maior lisura nas decisões (ANDRADE; SANTANA; FRANCO JUNIOR, 2016). Essas medidas foram adotadas visando a maior lisura no processo decisório.

$\mathrm{Na}$ prática para garantir competitividade, todo e qualquer benefício encontrado pela companhia para sobrepor-se aos seus concorrentes devem ser utilizado, inclusive o planejamento tributário (GOUVEIA; AFONSO, 2013). Em virtude disso a grande maioria dos empresários busca o planejamento tributário meramente para o não pagamento dos impostos, ou seja, não realiza um efetivo planejamento tributário (GRAHAM et al. 2014). Tal afirmação decorre do fato dos entes tributantes requisitarem, para a validação do planejamento, não mais o cumprimento das formas da lei, mas essencialmente que haja uma substância econômica na operação que foi convencionalmente denominado propósito negocial. (MORAES, 2014).

No sentido de ser importante observar o propósito negocial em um planejamento tributário, não somente para efeitos legais, mas para efeitos práticos, observa-se os dizeres de Calijuri (2009, p. 74): “quando um gestor foca seu objetivo em minimizar tributos, ele não está focando em maximizar as vendas, melhorar a qualidade de seus produtos ou produzir com maior produtividade e eficácia”.

Dessa forma, é indiscutível que além da perda no que é referente à análise que o mercado deverá fazer acerca da empresa, também nota-se que nem sempre o não pagamento de tributo resultará em maior benefício econômico (RANDOLPH; SEIDA, 2007). Em razão disso, o planejamento tributário agressivo e que tem por única intenção não efetuar o pagamento de tributos, no entendimento de Graham et. al. (2014), provavelmente será encarado negativamente pelo mercado, motivo pelo qual ainda que se economize no pagamento de impostos, poderá significar perda em outras áreas.

O planejamento tributário deve ser analisado como uma forma de gerenciar a atividade empresarial e potencializar o próprio retorno do negócio, uma vez que pensar de forma distinta e simplesmente realizar a engenharia tributária para a redução da carga a ser paga é uma ideia incompleta da sua função (SANTA; REZENDE, 2016). Sem dizer que o planejamento tributário também é uma oportunidade na qual administradores de má índole utilizam de subterfúgios para auferirem vantagens indevidas (DESAI; DHARMAPALA, 2009). 
Um planejamento tributário deve levar em consideração todas as partes, todos os tributos e todos os custos. Ainda, de acordo com Calijuri (2009), ter como intento unicamente a minimização do pagamento do tributo é uma visão apequenada de como deve funcionar a gestão de uma companhia. Nota-se que o planejamento tributário, para ser considerado eficaz, de acordo com Randolph e Seida (2007), não deve ter como foco apenas a minimização do pagamento de tributos, mas uma conjunção de benefícios fiscais e os custos de obtenção desses benefícios.

Os tributos são o preço que os cidadãos pagam para ter uma maior eficiência social e econômica, afinal, paga-se para ter uma supervisão estatal no que tange a garantir o direito de propriedade no intuito de que as pessoas possam viver livres de coerção, inclusive para participar do mercado. Dessa forma, o planejamento, para ser considerado realmente eficaz, deve otimizar a atividade empresarial e fazer com que a mesma cumpra com suas obrigações. Aliado a isso, é de suma relevância, para o seu sucesso, que os cidadãos passem a ter uma educação tributária e que entendam o quanto o seu adimplemento é necessário para realizar a manutenção das atividades estatais (RANDOLPH; SEIDA, 2007).

Nos dizeres de Quintino e Macei (2015) para que o planejamento tributário seja considerado válido, é necessária uma análise muito além da mera forma do negócio jurídico que está sendo estabulado. É necessária uma análise da substância da coisa que, por sua vez, é conhecido com o propósito negocial.

Frisa-se que essa afirmação no sentido de ser necessária a análise da substância é corroborada pelos julgamentos proferidos pelo CARF, uma vez que eles trazem em seus acórdãos menções acerca do planejamento tributário ser algo lícito, desde que não tenha por intento unicamente o não pagamento do imposto. Ato contínuo Menezes (2016) afirma que a apresentação de justificativa econômica para o planejamento tributário passou a ser o critério utilizado pelo CARF para o julgamento sobre a validade e invalidade do planejamento tributário, necessitando-se, assim, de forma nítida de motivação extra tributária, tal como exposto acima.

Inclusive, tentando inibir essa busca desenfreada do não pagamento de tributos, mediante planejamentos tributários abusivos, houve uma intensificação da atividade de fiscalização e consequentemente autuação de atividades consideradas anômalas. Registre-se nesse sentido, artigo 116, parágrafo único, do Código Tributário Nacional, que censura o intuito de fazer valer a primazia da forma sobre a substância (QUINTINO;MACEI, 2015). Nota-se que esse posicionamento passou a ser mais constante adotado a partir do ano de 2004 porque se iniciou uma análise mais detida sobre o propósito negocial, logo, os aspectos substanciais do negócio jurídico realizado do que simplesmente a licitude da forma que, por sua vez, tinha como objetivo exclusivo o não pagamento de tributos (ABRAHAM, 2011).

Esse entendimento não é pacífico, havendo, por exemplo, doutrinadores com pensamento em sentido contrário, tal como Carvalho (2010) que diz ser inadmissível a desconsideração de um planejamento tributário pela autoridade administrativa se o mesmo se encontra dentro dos parâmetros estabelecidos pela Legislação. Carvalho (2010) assevera, ainda, que o próprio aspecto econômico é uma forma retirada da realidade social segundo critérios da ciência econômica e não se encontra em conformidade com a ciência jurídica. Diante disso, o negócio realizado meramente para o não pagamento de tributo, estando em uma forma permitida por Lei, seria válido.

Porém, como exposto, tanto Schoueri et. al. (2010), quanto Martinez e Coelho (2016), ressaltam com base na análise da jurisprudência, a relevância que haja em um planejamento tributário uma justificativa extrafiscal para que o mesmo seja considerado válido. Para tanto, a atitude adotada pela companhia, através de uma reorganização societária, por exemplo, deve ter objetivos de trazer uma maior efetividade ao negócio que não apenas a minimização da carga tributária. Posto isso, analisando-se as considerações realizadas, foram criadas as seguintes hipóteses de pesquisas:

Hipótese 1: O Novo CARF mantém o seu critério de julgamento após a Operação Zelotes no que toca aos planejamentos tributários por reorganização societária. 
Hipótese 2: Há fatores não expressos na fundamentação dos votos vencedores que influenciam no resultado do julgamento de planejamentos tributários por reorganização societária.

Com base nas respostas encontradas no presente estudo, analisando-as em confronto com os achados por Schoueri et. al. (2010) e Martinez e Coelho (2016), pode-se diminuir de forma concreta o risco da invalidação de um planejamento tributário, caso se considere, para a sua realização, as propriedades identificadas. Outrossim, como se nota na hipótese 2, foram encontradas respostas acerca da influência de fatores contextuais no julgamento, tais como: que redigiu o voto vencedor, quem foi o relator, resultado da votação, voto de qualidade e valor do crédito tributário apreciado.

Finaliza-se observando que resta nítido, que tanto na literatura nacional quanto internacional, que está tem se debruçado sobre a temática dos critérios de validade de planejamentos tributários no intuito de identificar a melhores práticas a serem adotadas pelas companhias para minimizar o risco fiscal..

\section{Metodologia}

\section{Normatyve system}

Nesse tópico seguiu-se o modelo apresentado por Schoueri et. al. (2010) e, replicado em Martinez e Coelho (2016) e almejou-se manter-se o mais fidedigno possível a forma de análise por eles realizada no que se refere às propriedades. Os resultados desses estudos são comparados nesta pesquisa com os achados aqui documentados, razão pela qual, no intuito de auferir uma maior comparabilidade nos resultados encontrados, o método por eles utilizado foi aqui reproduzido de modo mais fidedigno possível.

Assim, foi utilizada a metodologia de Alchourrón e Bulygin (1975), conhecida como "normative systems". De acordo com Schoueri et. al. (2010, p. 506), "um sistema normativo consiste em um sistema lógico-dedutivo, ou seja, um sistema formal com consequências lógicas, em que existe pelo menos uma norma (estrutura hipotético-condicional)". Segundo Coelho (2013, p. 25), esse método foi criado "para sistematizar, organizar e evidenciar inconsistências em sistemas normativos".

Diante disso, o "normative systems" propõe, nos dizeres de Schoueri et. al. (2010, p. 505) "que a sistematização pode ser uma maneira eficaz para reconstruir e solucionar diversas questões enfrentadas pela ciência jurídica".

De qualquer forma, nota-se que Schoueri et. al. (2010) realizou algumas alterações no modelo inicialmente proposto por Alchourrón e Bulygin (1975), razão pela qual uma vez que o nosso trabalho paradigma, Martinez e Coelho (2016), utilizou-se daquele e não deste, desse modo é imperioso que seja seguida a mesma metodologia no intuito dos resultados encontrados tenham os mesmos parâmetros de análise e comparabilidade.

Observa-se que este método é indicado para este tipo de análise e que apenas o reproduzindo nas formas realizadas por Martinez e Coelho (2016) poder-se-ia comparar os resultados ora encontrados com os expostos no estudo paradigma. Outrossim, ainda que hajam outras formas de análise de conteúdo, uma vez que não foram utilizados nos trabalhos anteriores, foi considerado inapropriada a sua utilização no presente estudo, sob pena de fugir ao que foi proposto.

Também vale dizer que esses métodos de análise de conteúdo trazem uma obrigação forte no sentido de analisar o que está escrito e da forma que está escrito, enquanto que no sistema adotado no presente estudo permite-se a interpretação e/ou sistematização dos pensamentos para ulterior interpretação (MARTINEZ; COELHO, 2016).

Posto isso, o método adotado para realizar a análise dos acórdãos foi o "normative system”, em virtude da necessidade de se manter uma fidedignidade aos estudos anteriores. 


\section{Delimitação das observações}

No tocante as observações foram escolhidas analisar acórdãos posteriores a Operação Zelotes, portanto, do período de dezembro de 2015 a dezembro de 2017. Nota-se, que a delimitação das observações teve que seguir critérios adotados por Schoeuri et. al. (2010) e Martinez e Coelho (2016), ou seja, foi considerado como planejamento tributário atividades voluntárias ou não, que tenham por finalidade reduzir, postergar ou afastar os tributos.

Os dados foram coletados junto ao Conselho Administrativo de Recursos Federais, CARF, especificamente em seu sítio eletrônico, www.carf.fazenda.gov.br, opção "Jurisprudência", depois "Acórdãos", por meio de palavras chaves estabelecidas, quais sejam: "cisão", "fusão" e "incorporação", bem como acrescentadas outras, tais como: planejamento fiscal cisão, planejamento fiscal fusão, planejamento fiscal incorporação e planejamento tributário. Isso porque entendeu-se que qualquer acórdão que considera ou sugira atividade de planejamento tributário em seu teor deverá ter, em sua ementa, tais referências (MARTINEZ; COELHO, 2016).

Com essa busca inicial conseguiu-se realizar a coleta do seguinte número de observações: incorporação 04 observações; planejamento fiscal 23 observações; planejamento fiscal cisão 08 observações; planejamento fiscal fusão 07 observações; planejamento fiscal incorporação 08 observações e planejamento tributário 48 observações, portanto, 98 observações foram encontradas no total.

Todavia, no momento de separação das observações foram retiradas aquelas que não possuíam aplicabilidade direta com o estudo (tratavam de matéria diversa) e também aquelas que, em virtude do assemelhamento das palavras, apareceu em duplicidade. Logo, ficaram 70 observações (Acórdãos) para serem analisadas.

Outrossim, considera-se que pode ter ocorrido de alguns julgamentos referente a planejamento tributário podem ter ficado a margem da análise, uma vez que se reconhece que este método não engloba a totalidade da população.

\section{Observações de acordãos}

Conforme exposto em tópicos anteriores, tem-se a seguir as observações analisadas, com os respectivos números dos Acórdãos junto ao CARF e ano de julgamento. Conjuntamente ao presente trabalho, especificamente no Anexo 1, observam-se os fatos narrados de forma sintética, o resultado do planejamento, as análises das propriedades e controles apurados.

Tabela 1 - Observações de Acórdãos entre 2015 a 2017

\begin{tabular}{|c|c|c|c|c|c|c|c|c|}
\hline $\mathbf{N}^{\mathbf{o}}$ & ACÓRDÃO & ANO & $\mathrm{N}^{\mathbf{0}}$ & ACÓRDÃO & ANO & $\mathrm{N}^{\mathbf{0}}$ & ACÓRDÃO & ANO \\
\hline 1 & 9.101 .002 .960 & 2017 & 25 & 1.402 .002 .244 & 2016 & 49 & 1.301 .002 .608 & 2017 \\
\hline 2 & 9.101 .002 .962 & 2017 & 26 & 1.401 .001 .935 & 2017 & 50 & 1.301 .001 .852 & 2015 \\
\hline 3 & 1.301 .002 .279 & 2017 & 27 & 1.302 .002 .126 & 2017 & 51 & 1.401 .001 .575 & 2016 \\
\hline 4 & 1.301 .002 .281 & 2017 & 28 & 9.101 .002 .814 & 2017 & 52 & 1.402 .002 .152 & 2016 \\
\hline 5 & 1.402 .002 .513 & 2017 & 29 & 1.302 .002 .071 & 2017 & 53 & 1.301 .002 .009 & 2016 \\
\hline 6 & 1.301 .002 .433 & 2017 & 30 & 2.402.005.697 & 2017 & 54 & 1.402 .002 .145 & 2016 \\
\hline 7 & 9.101 .002 .802 & 2017 & 31 & 1.301 .002 .238 & 2017 & 55 & 1.402 .002 .158 & 2016 \\
\hline 8 & 1.201 .001 .618 & 2017 & 32 & 2.202.003.605 & 2017 & 56 & 1.402 .002 .183 & 2016 \\
\hline 9 & 1.402 .002 .455 & 2017 & 33 & 1.201 .001 .559 & 2017 & 57 & 1.401 .001 .534 & 2016 \\
\hline 10 & 1.402 .002 .443 & 2017 & 34 & 1.401 .001 .738 & 2016 & 58 & 1.301 .002 .111 & 2016 \\
\hline 11 & 1.302 .002 .045 & 2017 & 35 & 1.402 .002 .325 & 2016 & 59 & 1.201 .001 .474 & 2016 \\
\hline 12 & 1.302 .001 .978 & 2016 & 36 & 1.401 .001 .697 & 2016 & 60 & 1.301 .002 .155 & 2016 \\
\hline 13 & 1.401 .001 .718 & 2016 & 37 & 1.402 .002 .337 & 2016 & 61 & 1.201 .001 .534 & 2016 \\
\hline 14 & 1.301 .002 .156 & 2016 & 38 & 3.401 .003 .266 & 2016 & 62 & 1.402 .002 .336 & 2016 \\
\hline 15 & 1.401 .001 .675 & 2016 & 39 & 9.101 .002 .429 & 2016 & 63 & 1.401 .001 .967 & 2016 \\
\hline
\end{tabular}




\begin{tabular}{lll|lll|lll}
16 & 1.402 .002 .215 & 2016 & 40 & 1.402 .002 .207 & 2016 & 64 & 1.201 .001 .554 & 2017 \\
17 & 1.402 .002 .244 & 2016 & 41 & 2.202 .003 .388 & 2016 & 65 & 1.301 .002 .670 & 2017 \\
18 & 1.402 .002 .187 & 2016 & 42 & 1.401 .001 .601 & 2016 & 66 & 1.401 .002 .085 & 2017 \\
19 & 2.202 .003 .318 & 2016 & 43 & 2.301 .004 .530 & 2016 & 67 & 1.302 .002 .322 & 2017 \\
20 & 1.401 .001 .584 & 2016 & 44 & 2.301 .004 .480 & 2016 & 68 & 3.402 .004 .374 & 2017 \\
21 & 2.202 .003 .135 & 2016 & 45 & 2.301 .004 .482 & 2016 & 69 & 1.402 .002 .490 & 2017 \\
22 & 2.202 .003 .134 & 2016 & 46 & 2.301 .004 .483 & 2016 & 70 & 9.101 .003 .274 & 2017 \\
23 & 1.301 .002 .434 & 2017 & 47 & 2.102 .004 .481 & 2016 & & &
\end{tabular}

Nota: Disponível no site do CARF (www.carf.fazenda.gov.br)

Fonte: Elaborado pelos autores

\section{Das propriedades e dos controles}

Ultrapassados os tópicos anteriores, tem-se que as propriedades analisadas constituem-se de perguntas que foram respondidas de forma positiva ou negativa, após a respectiva leitura do acórdão, consideração às informações explícitas e implícitas que levaram os conselheiros a decidirem pela validação ou invalidação do planejamento tributário (MARTINEZ; COELHO, 2016).

As propriedades escolhidas para análise são as mesmas trazidas por Schoueri et. al. (2010) e Martinez e Coelho (2016) porque permitem a manutenção do sistema de verificação das informações encontradas, logo, traz maior objetividade e robustez para as respostas.

Dito isso, como se depreende do trabalho de Martinez e Coelho (2016), as propriedades analisadas foram:

\section{- $\quad$ Propriedade 1 (P1): Os fatos foram considerados existentes tais como narrados pelo contribuinte?}

O Conselho de Contribuintes pode julgar inválido o planejamento tributário se entender que os atos praticados pelo contribuinte não são verdadeiros ou foram praticados somente 'no papel', não havendo correspondência entre as declarações dos contribuintes e a realidade.

Tal propriedade corresponde, na doutrina, à ocorrência de 'simulação'. Contudo, a desconsideração também pode resultar da falta de 'propósito negocial', sem que o Conselho adote expressamente tal teoria nos julgamentos, criando uma zona cinzenta entre os dois institutos. (SHOUERI; FREITAS, 2010, p. 26).

\section{- $\quad$ Propriedade 2(P2): Foram observadas normas cogentes não tributárias?}

Em alguns planejamentos tributários houve o descumprimento de regras cogentes não tributárias, tais como normas do Banco Central do Brasil e da CVM (Comissão de Valores Mobiliários). Nesses casos, o planejamento tributário pode ser julgado inválido.

Essa pergunta pode ser entendida como a análise, pelo Conselho de Contribuintes, da existência de 'fraude à lei' não tributária. Contudo, conforme se verifica da análise dos resultados da pesquisa, a aplicação desse conceito geralmente é utilizada para justificar a existência de simulação. (SHOUERI; FREITAS, 2010, p. 26).

\section{- $\quad$ Propriedade 3 (P3): A operação teve outros propósitos não tributários?}

Há casos em que o Conselho entende que a mera economia tributária não é motivo suficiente para realizar uma operação; em outros, afirma que tal propriedade é irrelevante. Dessa forma, é necessário avaliar se a decisão considerou os 'motivos' que levaram os contribuintes a praticar a operação, e se tal propriedade interfere na validade do planejamento tributário. 
Com essa propriedade, pretende-se abordar a teoria do 'propósito negocial'. Esta teoria está muitas vezes associada ao 'motivo subjetivo' das partes, e são o parâmetro para desconsideração do planejamento tributário com base em figuras como o abuso do direito, abuso de formas ou a fraude à lei tributária. Em outros casos, o Conselho de Contribuintes emprega a falta de motivos extra tributários como indício da prática de simulação. (SHOUERI; FREITAS, 2010, p. 26)

- $\quad$ Propriedade 4 (P4): Houve adequado intervalo temporal entre as operações?

Foi comum que se considerasse não ter havido outros motivos além da economia tributária por terem as operações ocorridas dentro de um intervalo temporal inadequado, v.g., operações societárias que geralmente demoram meses para ocorrer foram realizadas no intervalo de algumas horas ou dias. (SHOUERI; FREITAS., 2010, p. 30).

\section{- $\quad$ Propriedade 5 (P5): As partes envolvidas eram independentes?}

Outra propriedade importante foi a realização das operações entre partes que guardavam alguma vinculação entre si, como operações entre empresas do mesmo grupo, pessoas da mesma família, etc. (SHOUERI; FREITAS, 2010, p. 30).

Nota-se que de acordo com Martinez e Coelho (2016, p. 204), “as perguntas representativas das propriedades foram elaboradas, de forma intencional, para as repostas positivas tendessem a levar à validade da atividade de tax avoidance, e vice-versa".

Nota-se que P1, P2, P3, P4 e P5 referem-se às propriedades (perguntas) acima descritas, sendo o (S) considerado como resposta positiva e o $(\mathrm{N})$ considerado como resposta negativa (não). Já o $(\mathrm{V})$ tange a validação do planejamento tributário e o (I) pela invalidação.

Frisa-se, também, que no trabalho de Schoueri et. al. (2010) as propriedades 4 e 5 eram decorrentes da P3. Todavia, uma vez que Martinez e Coelho (2016) optaram por adotá-las como propriedades e não subpropriedades adequou-se o presente estudo a este e não aquele, como já explicado.

Também vale mencionar que Schoueri et. al. (2010) trazia outra propriedade que foi retirada do trabalho de Martinez e Coelho (2016), portanto, uma vez que se tentou ser o mais fidedigno possível a este e não aquele, especialmente pelo fato deste ter um modelo de regressão mais adequado ao estudo.

De qualquer modo, no decorrer do trabalho foram acrescentadas outras 05 variáveis, que foram denominadas controles para trazer um maior diferencial ao presente estudo quando comparado com os anteriores. Esses controles, por sua vez, foram os seguintes:

- $\quad$ Controle 1 (C1): O julgamento foi decidido pelo Voto de Qualidade?

O voto de qualidade consiste-se no voto de minerva. Uma vez que as turmas são compostas por 8 (oito) membros, em caso de empate cabe ao presidente da turma o desempate por meio do voto qualificado que, por sua vez, é o voto com valor duplicado. Enquanto aos demais conselheiros o voto tem peso 01, no caso de empate é atribuído ao voto do presidente um peso 02. Nota-se que o presidente é sempre representante da Fazenda.

\section{- $\quad$ Controle 2 (C2): Quem fez o voto vencedor condutor do Acordão?}

Nem sempre quem é o relator faz o voto vencedor. Isso porque o relator pode não ser acompanhado pelos demais conselheiros em suas razões de julgamento. Assim, o voto vencedor poderia ser proveniente da Fazenda ou dos Contribuintes.

- Controle 3 (C3): Quem foi o relator do processo? 
O relator é o conselheiro sorteado para relatar o caso aos demais conselheiros e, antes dos demais, explicar suas razões para a tomada de decisão em um ou outro sentido. O relator pode ser proveniente da Fazenda ou dos Contribuintes.

- Controle 4 (C4): Qual foi o placar da votação?

As turmas têm 08 (oito) conselheiros. Porém, nem sempre todos comparecem a sessão de julgamento. Nesse trabalho foi considerado placar de votação a subtração entre os votos vencedores e o voto vencedor, sendo o resultado dessa subtração o placar de votação considerado para fins de regressão linear.

\section{- $\quad$ Controle 5 (C5): Qual foi o valor do crédito tributário na lide?}

O valor é o crédito tributário discutido. Em alguns processos este valor vem definido e, por isso, é de fácil constatação. Em outros há necessidade de somar os autos de infração que deram azo ao processo administrativo. Também há aqueles em que nenhum valor específico é dito e, portanto, não há possibilidade e de realizar essa análise. Posto isso, com base nas propriedades e controles acima informados, foi realizada uma análise estatística nos termos abaixo expostos.

\section{Métodos estatísticos}

O presente estudo visa corroborar com os achados dos estudos de Schoueri et. al. (2010) e Martinez e Coelho (2016), além disto, avaliar diretamente como as características fáticas dos casos com base na fundamentação e conclusão dos julgadores, influenciam a decisão de validação e invalidação do planejamento tributário dos acórdãos.

Sendo assim, inicialmente foi realizado análise exploratória das observações onde trabalharam-se os conceitos de estatística descritiva para organizar e descrever o conjunto de dados, alusivo à análise de conteúdo pelo critério "normative systems" com propósito de avaliar a distribuição de frequência das propriedades nas observações.

Em seguida, deu continuidade às análises por meio do cálculo do coeficiente de correlação entre as propriedades e resultado, que tem como propósito medir a força e a direção de relação linear entre duas propriedades/variável. A amplitude do coeficiente varia entre -1 para 1, sendo que, correlação próximo de -1 indica relação negativa e próximo de 1 relação positiva. O coeficiente de correlação próximo de zero é um sugestivo que não há relação linear (LARSON: FARBER, 2010).

Ainda segundo Larson e Farber (2010), o fato de dois indicadores serem fortemente correlacionados não implica uma relação de causa e efeito entre estes. Larson e Farber (2010) considera quatro possíveis situações abarcando correlação significativa entre duas variáveis: (1) relação direta de causa e efeito; (2) relação direta de causa e reversa; (3) a relação de causa e efeito é influenciada por outras variáveis; e (4) a relação de causa e efeito é simplesmente uma mera coincidência. Partindo dessas diretrizes, delineou-se o método de regressão linear para investigar relação entre as propriedades e resultado de decisão dos julgadores, sob a perspectiva de que, pelo menos uma das três primeiras situações citadas produzisse evidências estatísticas que pudessem contribuir na busca por respostas as hipóteses de pesquisa enumeradas.

De modo geral, a análise de regressão envolve estudos que de um lado se tem variável dependente (resultado), em relação a uma ou mais variáveis independentes (propriedades), visando estimar e/ou prever o valor médio da primeira em termos dos valores conhecidos, ou fixados da segunda (GUJARATI; PORTER, 2011).

Neste estudo, a variável dependente foi representada pelo resultado de validação e invalidação do planejamento tributário tal como prescrito por dar provimento ou negar provimento aos recursos 
voluntários do contribuinte, e as variáveis independentes sendo representada pelas propriedades e controles. No total, foram estimadas duas rodadas de modelos: a primeira roda associada à hipótese 1, qual seja: variáveis independentes representadas pelas propriedades P1 a P5; e a segunda rodada conectada a hipótese 2: variáveis independentes representadas pelas propriedades C1, C2, C3, C4 e C5.

Por fim, uma vez que a metodologia acima mencionada pode ser considerada válida ante aos estudos anteriormente publicados e que a utilizam, bem como a relevância acadêmica e prática do que se pretende na presente pesquisa, fundamental se faz a análise dos resultados expostos no tópico a seguir.

\section{Apresentação dos resultados}

Neste capítulo são apresentados os resultados do presente estudo. Na primeira parte, caracteriza a observação dos acórdãos a partir das propriedades, valor e resultado de decisão. Em seguida, apresenta uma matriz com os coeficientes de correlação entre os pares de indicadores e, por último, os resultados dos modelos de regressão.

\section{ESTATÍSTICA DESCRITIVA}

A Tabela 2 apresenta a estatística descritiva dos indicadores com propósito de caracterizar à distribuição dos acórdãos por variável. No que diz respeito a variável dependente "resultado", nota-se que 28,6\% das decisões de planejamento tributário foram classificadas como válidas. Referente às propriedades que corroboram com a decisão de validação, ou seja, com afirmações positivas, verificou-se que 37,7\% acórdãos foram positivos para P1, 42,4\% para P2 e 29,0\% para P3.

Uma vez respondida à propriedade P3 (A operação teve outros motivos não tributários?), passa-se as propriedades $\mathrm{P} 4$ e P5. No que diz respeito à propriedade P4, que avalia se houve um intervalo adequado temporal entre as operações, de um total 45 acórdãos examinados, 31,1\% destes apresentaram prazo adequado entre as operações. Quanto a propriedade P5, verifica-se que 40,7\% de um total de 54 acórdãos, as partes envolvidas eram independentes..

Tabela 2 - Estatística Descritiva dos Indicadores

\begin{tabular}{lllrccccc}
\hline Variáveis & N & Média & $\begin{array}{c}\text { Desvio } \\
\text { Padrão }\end{array}$ & Mínimo & $\begin{array}{c}\text { Percentil } \\
\mathbf{2 5}\end{array}$ & Mediana & $\begin{array}{c}\text { Percentil } \\
\mathbf{7 5}\end{array}$ & Máximo \\
\hline Resultado & 70 & 0,286 & 0,455 & 0 & 0 & 0 & 1 & 1 \\
P1 & 69 & 0,377 & 0,488 & 0 & 0 & 0 & 1 & 1 \\
P2 & 66 & 0,424 & 0,498 & 0 & 0 & 0 & 1 & 1 \\
P3 & 69 & 0,290 & 0,457 & 0 & 0 & 0 & 1 & 1 \\
P4 & 45 & 0,311 & 0,468 & 0 & 0 & 0 & 1 & 1 \\
P5 & 54 & 0,407 & 0,496 & 0 & 0 & 0 & 1 & 1 \\
P6 & 53 & 0,434 & 0,500 & 0 & 0 & 0 & 1 & 1 \\
C1 & 70 & 0,171 & 0,380 & 0 & 0 & 0 & 0 & 1 \\
C2 & 70 & 0,614 & 0,490 & 0 & 0 & 1 & 1 & 1 \\
C3 & 70 & 0,514 & 0,503 & 0 & 0 & 1 & 1 & 1 \\
C4 & 70 & 4,414 & 2,753 & 0 & 2 & 5 & 7 & 8 \\
C5 & 53 & 17,345 & 2,286 & 11,22 & 15,78 & 17,38 & 18,55 & 23,65 \\
\hline
\end{tabular}

Nota: Resultado - Válido: Planejamento Tributário Aceito - S (Sim) - 1 e Inválido: Planejamento Tributário Rejeitado - N (Não) - 0. P1 - Os fatos foram considerados existentes tais como narrados pelo contribuinte? P2 Foram observadas normas cogentes não tributárias? P3 -A operação teve outros propósitos não tributários? P4 Houve adequado intervalo temporal entre as operações? P5 - As partes envolvidas eram independentes? P6 Existe coerência entre as operações e as atividades empresariais das partes envolvidas? C1 - Foi decidida por voto de qualidade? C2 - Quem fez o voto vencedor? C3 - Quem foi o relator?; C4 - Qual o placar da votação?; C5 - $\ln$ (valor) - logaritmo neperiando do valor do crédito tributário.

Fonte: Elaborado pelos autores 
Por fim, no tocante as variáveis que representam contribuição adicional ao tema em questão, nota-se que de um total de 70 acórdãos, $17,1 \%$ destes a decisão o foi por meio do voto de qualidade, $61,4 \%$ pelo voto vencedor e $51,4 \%$ o relator foi da fazenda, tendo a média do placar sido de $4,14 / 8$ votos para posição vencedora. $\mathrm{Na}$ análise das estatísticas descritivas no relativo aos itens $\mathrm{C} 1$ a C6, o artigo avança em relação à literatura anterior, apreciando particularidades não antes estudas cientificamente.

\section{Matriz de correlação}

Nesta subseção apresenta-se a matriz de correlação entre as propriedades de validade do planejamento tributário e o resultado de julgamento dos acórdãos. Quando a resposta à propriedade era positiva, assumiu valor 1 (um), e quando era negativa, assumiu valor 0 (zero). Referente à variável resultado, caso o planejamento tributário fosse considerado válido, o valor atribuído era 1 (um), o inválido 0 (zero).

Em uma análise geral, das propriedades compreendidas como referência na decisão para validade do planejamento tributário, P1, P2, P3, P4 e P5, em todos os coeficientes correlação resultaram significativos e positivos, ou seja, a afirmação positiva para essas propriedades influenciam a decisão na validação do acórdão.

Logo, no advento da realização de um planejamento tributário é importante que sejam analisadas as propriedades acima elencadas no intuito de que se aumente a possibilidade de sua validação do planejamento tributário.

No que toca aos controles quando a decisão ocorre por voto de qualidade, atribui-se o valor 1 (um), caso contrário, 0 (zero). No que toca ao quem foi responsável pelo voto vencedor e pelo relator, sendo representante da fazenda 1 (um), dos contribuintes 0 (zero), finalmente no relativo ao placar, tem-se a razão entre votos vencedores e votos vencidos.

Tabela 3 - Matriz de Correlação de Pearson

\begin{tabular}{|c|c|c|c|c|c|c|c|c|c|c|c|c|}
\hline Variável & 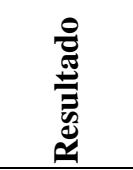 & $\underline{E}$ & $\tilde{\Sigma}$ & $\tilde{\varepsilon}$ & \pm & $\stackrel{2}{2}$ & $\stackrel{0}{2}$ & $\bar{u}$ & ป̂ & $\ddot{U}$ & $\Xi$ & v \\
\hline Resultado & 1,00 & & & & & & & & & & & \\
\hline P1 & $0,82 * *$ & 1,00 & & & & & & & & & & \\
\hline $\mathrm{P} 2$ & $0,70 * *$ & $0,62 * *$ & 1,00 & & & & & & & & & \\
\hline P3 & $0,72 * *$ & $0,75^{* *}$ & $0,63^{* *}$ & 1,00 & & & & & & & & \\
\hline P4 & $0,53 * *$ & $0,57 * *$ & $0,58 * *$ & $0,69 * *$ & 1,00 & & & & & & & \\
\hline P5 & $0,49 * *$ & $0,50 * *$ & $0,51 * *$ & $0,53 * *$ & $0,64 * *$ & 1,00 & & & & & & \\
\hline P6 & $0,75^{* *}$ & $0,89 * *$ & $0,84 * *$ & $0,74 * *$ & $0,55^{* *}$ & $0,55^{* *}$ & 1,00 & & & & & \\
\hline $\mathrm{C} 1$ & $-0,29 * *$ & $-0,18$ & $-0,17$ & $-0,13$ & $-0,19$ & $-0,10$ & 0,02 & 1,00 & & & & \\
\hline $\mathrm{C} 2$ & $-0,34 * *$ & $-0,17$ & $\overline{0}-31 * *$ & $-0,21$ & $-0,20$ & $-0,21$ & $-0,21$ & $0,36^{* *}$ & 1,00 & & & \\
\hline $\mathrm{C} 3$ & $-0,21$ & $-0,01$ & $-0,18$ & $-0,09$ & $-0,14$ & $-0,08$ & $-0,05$ & 0,22 & $0,82^{* *}$ & 1,00 & & \\
\hline $\mathrm{C} 4$ & 0,11 & $-0,05$ & 0,20 & $-0,03$ & $-0,02$ & 0,05 & $-0,03$ & $-0,49$ & $-0,34 * *$ & $0,27 * *$ & 1,00 & \\
\hline $\mathrm{C} 5$ & 0,23 & $0,37 * *$ & 0,15 & $0,29 * *$ & 0,04 & 0,11 & 0,30 & 0,22 & 0,07 & 0,04 & $-0,28 * *$ & 1,00 \\
\hline
\end{tabular}

Nota: (i)P1 - Os fatos foram considerados existentes tais como narrados pelo contribuinte? P2 - Foram observadas normas cogentes não tributárias? P3 -A operação teve outros propósitos não tributários? P4 - Houve adequado intervalo temporal entre as operações? P5 - As partes envolvidas eram independentes? P6 - Existe coerência entre as operações e as atividades empresariais das partes envolvidas? C1 - Foi decidida por voto de qualidade? C2 - Quem fez o voto vencedor? C3 - Quem foi o relator? C4 - Qual o placar da votação? C5 - $\ln$ (valor) - logaritmo neperiando do valor do crédito tributário.

(ii) **Significativo ao nível de $5 \%$.

Fonte: Elaborado pelos autores. 
Ao avaliar as variáveis de controle adicionais e consideradas como relevantes neste estudo, nota-se que o voto de qualidade (C1) influência negativamente a decisão dos acórdãos, como o voto vencedor (C2). Assim, se o relator ou voto vencedor forem provenientes da Fazenda a possibilidade de validação do planejamento tributário diminui. As demais variáveis de controles não se mostraram significante com o resultado da decisão de validação ou invalidação do planejamento tributário. Os resultados verificados no estudo, confirmam em parte a crença generalizada de que as decisões por votos de qualidade, quando ocorrem, tendem a ser contra os interesses do contribuinte.

\section{Modelo de regressão}

Nas tabelas subsequentes são apresentados os coeficientes estimados para os modelos de regressão estimados e delineados como relevantes para responder as hipóteses de pesquisa. Os resultados da Tabela 4 está associado à hipótese 1: O Novo CARF mantém o seu critério de julgamento após a Operação Zelotes e a Tabela 5 a hipótese 2: Há fatores não expressos na fundamentação dos votos vencedores que influenciam no resultado do julgamento.

Tabela 4 Estimativas dos Modelos com as Propriedade

\begin{tabular}{llllllll}
\hline Variável & M1 & M2 & M3 & M4 & M5 & M6 & M7 \\
\hline Constante & 0,000 & 0,026 & 0,082 & 0,129 & 0,156 & $-0,051$ & 0,045 \\
P1 & $0,769 * * *$ & - & - & - & - & $0,521^{* * *}$ & $0,624 * * *$ \\
P2 & - & $0,652 * * *$ & - & - & - & $0,261 * * *$ & $0,348^{* *}$ \\
P3 & - & - & $0,718 * * *$ & - & - & 0,121 & $-0,050$ \\
P4 & - & - & - & $0,514 * * *$ & - & - & 0,038 \\
P5 & - & - & - & - & $0,480 * * *$ & - & $-0,043$ \\
\hline R-Quadrado & $67,5 \%$ & $49,2 \%$ & $51,6 \%$ & $27,5 \%$ & $24,4 \%$ & $73,1 \%$ & $74,9 \%$ \\
\hline
\end{tabular}

Nota:

(i) $* * * \mathrm{e}^{* * *}$ significativo ao nível de $1 \%, 5 \%$ e $10 \%$ respectivamente.;

(ii) M1:Resultado ${ }_{i}=\beta_{0}+\beta_{1} P 1+\varepsilon_{I}$; $12:$ Resultado $_{i}=\beta_{0}+\beta_{2} P 2+\mathcal{E}_{I}$; M3:Resultado $i=\beta_{0}+\beta_{3} P 3+$ $\varepsilon_{I} ; \quad$ M4:Resultado $i=\beta_{0}+\beta_{4} P 4+\varepsilon_{I} ; \quad$ M5:Resultado $i=\beta_{0}+\beta_{5} P 5+\varepsilon_{I} ; \quad$ M6: Resultado $_{i}=\beta_{0}+$ $\beta_{1} P 1+\beta_{2} P 2+\beta_{3} P 3+\varepsilon_{I} ;$ M7: Resultado $i=\beta_{0}+\beta_{1} P 1+\beta_{2} P 2+\beta_{3} P 3+\beta_{4} P 4+\beta_{5} P 5+\varepsilon_{I}$

(iii) P1 - Os fatos foram considerados existentes tais como narrados pelo contribuinte? P2 - Foram observadas normas cogentes não tributárias? P3 -A operação teve outros propósitos não tributários? P4 - Houve adequado intervalo temporal entre as operações? P5 - As partes envolvidas eram independentes?

Fonte: Elaborado pelos autores

As estatísticas das regressões dos modelos identificaram que as respostas afirmativas para as propriedades P1, P2, P3, P4 e P5 são estatisticamente significativas e positivas quanto ao planejamento tributário utilizado nas operações societárias. Assumindo o R-quadrado como parâmetro que determine a contribuição individual e/ou conjuntamente das propriedades, concluiu-se estatisticamente que P1 e P3 foram consideradas como as mais relevantes, isoladamente, para validade dos acórdãos, confirmando assim, a afirmativa da hipótese 1 de que CARF mantém o seu critério de julgamento após a Operação Zelotes. A P1 refere-se a inexistência de simulação, se isso é verificado, há grande probabilidade do planejamento tributário ser validado. Como segunda propriedade mais relevante, destaque-se a existência de outros propósitos além dos tributários para justificar a operação. Finalmente, conforme modelo M7, a verificação de que não há simulação e o respeito as demais normas cogentes não tributárias, propicia mais de $90 \%$ de probabilidade de que o planejamento tributário será aceito.

Outrossim, quando realizando uma análise comparativa com os estudos anteriores do CARF, Martinez e Coelho (2016) e Schoueri et. al. (2010), foi observado que os resultados encontrados permaneceram estáveis, logo, ao longo de 15 anos o Conselho de Contribuinte e CARF vem mantendo a sua forma de julgamento com base das propriedades elencadas. Isto é, as propriedades apuradas no Conselho de Contribuintes e CARF, este último no período que antecede a operação Zelotes, continuam a ser uma importante referência para definir critérios de validade de planejamento tributário. 
Como intuito de analisar fatores não expressos na fundamentação dos votos vencedores que influenciam no resultado do julgamento descrito pela teoria até então, a Tabela 5 apresenta as estimativas que podem ou não influenciar a decisão na validação do planejamento tributário dos acórdãos. As propriedades C1 (votos qualitativos), C2 (voto vencedor) e C3 (relator) são estatisticamente significativas para invalidar a operação de planejamento tributário.

Em uma análise múltipla, modelo 12, nota-se que, tanto o voto de qualidade, quanto voto vencedor se foi elaborado pela Fazenda são estatisticamente significativos para decisão de invalidação do planejamento tributário dos acórdãos. Também a partir desse modelo, conclui-se que, quanto maior o valor do crédito tributário dos acórdãos maior a chance de validação do planejamento tributário.

Por último, tem-se que todas às vezes que o voto de qualidade foi utilizado para a decisão do processo administrativo seu resultado foi de invalidação, isso porque tal voto é sempre proferido pelo presidente da câmara ou turma, logo, indicado pela Fazenda.

Tabela 5 - Estimativas dos Modelos com Variáveis Externas

\begin{tabular}{llllll}
\hline Variável & M8 & M9 & M10 & M11 & M12 \\
\hline Constante & $0,345 * * *$ & $0,481 * * *$ & $0,382 * * *$ & $0,204 *$ & $-0,533$ \\
C1 & $-0,345 * *$ & - & - & - & $-0,284 * * *$ \\
C2 & - & $-0,319 * * *$ & - & - & $-0,362 * * *$ \\
C3 & - & - & $-0,188 *$ & - & 0,089 \\
C4 & - & - & - & 0,019 & $-0,002$ \\
C5 & - & - & - & - & $0,061 * * *$ \\
\hline $\mathrm{R}-$ quadrado & $8,3 \%$ & $11,8 \%$ & $4,32 \%$ & $1,3 \%$ & $26,6 \%$ \\
\hline
\end{tabular}

Nota:

(i) *,** e *** significativo ao nível de $1 \%, 5 \%$ e $10 \%$ respectivamente.;

(ii) M8:Resultado ${ }_{i}=\beta_{0}+\beta_{1} C 1+\varepsilon_{I}$; M9:Resultado Re $_{i}=\beta_{0}+\beta_{2} C 2+\varepsilon_{I}$; M3:Resultado $i=\beta_{0}+\beta_{3} C 3+$ $\mathcal{E}_{I}$; M4:Resultado ${ }_{i}=\beta_{0}+\beta_{4} C 4+\mathcal{E}_{I}$; M5:Resultado $i=\beta_{0}+\beta_{5} P 5+\varepsilon_{I}$; M6: Resultado ${ }_{i}=\beta_{0}+\beta_{1} P 1+$ $\beta_{2} P 2+\beta_{3} P 3+\varepsilon_{I} ; \mathrm{M} 7:$ Resultado $_{i}=\beta_{0}+\beta_{1} P 1+\beta_{2} P 2+\beta_{3} P 3+\beta_{4} P 4+\beta_{5} P 5+\varepsilon_{I}$

(iii) C1 - Foi decidida por voto de qualidade? C2 - Quem fez o voto vencedor? C3 - Quem foi o relator?; C4 - Qual o placar da votação?;C5 In(valor) - logaritmo neperiando do valor do crédito tributário

Fonte: Elaborado pelos autores.

Face aos achados no tocante as características processuais do julgamento, se oferece um avanço na literatura, indicando critérios adicionais que podem explicar em parte a validade de um planejamento tributário.

\section{Análise dos resultados e contribuições da pesquisa}

Da reflexão sobre os resultados, constatou-se que os critérios de julgamento do Novo CARF se mantêm, em linhas gerais na forma preceituada em estudos anteriores, inobstante a reestruturação do processo administrativo tributário federal. Para tanto, observa-se abaixo o Quadro 1 que deixa nítido que todas às vezes que se responder afirmativamente as propriedades a seguir: P1: Os fatos foram considerados existentes tais como narrados pelo contribuinte? P2: Foram observadas normas cogentes não tributárias? P3: A operação teve outros propósitos não tributários? P4: Houve adequado intervalo temporal entre as operações? P5: As partes envolvidas eram independentes? Aumenta-se significativamente a possibilidade de validação do planejamento tributário.

Abaixo, segue Figura 1 na qual se demonstra que se a respectiva propriedade foi respondida afirmativamente (sim), em termos médios, como aumenta a probabilidade de validação do planejamento tributário. Para efeito comparativo, incluem-se os resultados documentados nos estudos em períodos anteriores. 


\begin{tabular}{|c|c|c|c|c|c|}
\hline \multicolumn{2}{|c|}{$\begin{array}{c}\text { RESULTADOS } \\
\text { NOVO CARF }\end{array}$} & \multicolumn{2}{c|}{ RESULTADOS } & \multicolumn{2}{c|}{ RESULTADOS } \\
\hline P 01 & $\begin{array}{c}\text { Válidos } \\
(76,9 \%)\end{array}$ & P 01 & $\begin{array}{c}\text { Válidos } \\
(71 \%)\end{array}$ & P 01 & $\begin{array}{c}\text { Válidos } \\
(100 \%)\end{array}$ \\
\hline P 02 & $\begin{array}{c}\text { Válidos } \\
(67,85 \%)\end{array}$ & P 02 & $\begin{array}{c}\text { Válidos } \\
(95 \%)\end{array}$ & P 02 & $\begin{array}{c}\text { Válidos } \\
(83,3 \%)\end{array}$ \\
\hline P 03 & $\begin{array}{c}\text { Válidos } \\
(70 \%)\end{array}$ & P 03 & $\begin{array}{c}\text { Válidos } \\
(93 \%)\end{array}$ & P 03 & $\begin{array}{c}\text { Válidos } \\
(90 \%)\end{array}$ \\
\hline P 04 & $\begin{array}{c}\text { Válidos } \\
(78,57 \%)\end{array}$ & P 04 & $\begin{array}{c}\text { Válidos } \\
(75 \%)\end{array}$ & P 04 & $\begin{array}{c}\text { Válidos } \\
67 \%)\end{array}$ \\
\hline P 05 & $\begin{array}{c}\text { Válidos } \\
(63,64 \%)\end{array}$ & P 05 & $\begin{array}{c}\text { Válidos } \\
(93 \%)\end{array}$ & P 05 & $\begin{array}{c}\text { Válidos } \\
(60 \%)\end{array}$ \\
\hline
\end{tabular}

\section{Figura 1: Análise Comparativa de Estudos}

Nota: (i) P1 - Os fatos foram considerados existentes tais como narrados pelo contribuinte? P2 - Foram observadas normas cogentes não tributárias? P3 -A operação teve outros propósitos não tributários? P4 Houve adequado intervalo temporal entre as operações? P5 - As partes envolvidas eram independentes?

(ii) Considera-se para essa comparação apenas quando as propriedades foram respondidas de forma positiva (sim), no qual fica demonstrado o aumento da probabilidade de validação do planejamento tributário.

Fonte: elaborada pelos autores

No que tange ao fato da decisão ser decidida pelo voto de qualidade e quem foi responsável por ser o redator ser conselheiro representante da fazenda, há alta probabilidade de ocorrer à invalidação do planejamento tributário proposto. Isso é corroborado também num ambiente em que o placar médio de votação para validação ou invalidação, a posição dos vencedores foi de 4,14/8 dos votos, evidenciando uma significativa divergência entre Conselheiros nas matérias que envolvem planejamento tributário.

Resultado instigante, foi verificar que a medida que o valor do crédito tributário discutido administrativamente aumenta, temos um aumento da probabilidade de validação do planejamento tributário, fato este que surpreendeu, de forma intuitiva e contra as demais evidências, face a maior interesse e radicalização que um maior crédito tributário desperta.

\section{Considerações finais}

Este estudo buscou apreciar os critérios de validade de planejamentos tributários decorrentes de reorganização societária adotados pelo Novo CARF, resultado das alterações após a Operação Zelotes. Adicionalmente, almejou identificar fatores processuais não expressos na fundamentação dos votos vencedores que podem estar correlacionados com o resultado do julgamento.

A pesquisa inovou em relação aos estudos anteriores por apresentar uma análise mais abrangente das propriedade e variáveis que podem influenciar os critérios de validade de um planejamento tributário. Além de propriedades substantivas, específicas do plano implementado pelo contribuinte para obter um tratamento tributário mais favorável, características processuais no tocante as condições formais nas quais se decide um julgamento administrativo, parecem também impactar nos resultados.

Esta investigação constitui-se assim em um contributo para uma literatura que procura explicar o comportamento de uma atividade judicante através da discussão de modelos teóricos e empíricos preditivos de como os conselheiros no CARF pensam e em particular decidem votar por validar (ou invalidar) um planejamento tributário. Identificam-se propriedades substanciais e características 
processuais do momento do julgamento que estatisticamente explicam em parte a decisão sobre determinada operação societária com implicações fiscais.

Estudar o comportamento dos Conselheiros no âmbito do CARF é um tema de suma importância no campo da gestão empresarial, na medida em que as questões tributárias são muito relevantes para continuidade de um negócio, com implicações financeiras e jurídicas para gestores e proprietários. O tipo de pesquisa desenvolvido busca entender a pragmática de funcionamento do processo administrativo tributário federal, e, nesse contexto, compreender a decisão de um Conselheiro é um passo crucial.

Os resultados auxiliam administradores, contadores, tributaristas e juristas, na identificação de critérios, que atendidos, minimizam a possível invalidação de um plano tributário, propiciando maior segurança jurídica. Adicionalmente, os resultados evidenciaram que identificação de quem faz o voto vencedor condutor do Acórdão, se houve o voto de qualidade e o valor do crédito tributário, parecem influenciar na validação ou invalidação do planejamento tributário. Os achados reiteram a importância do propósito negocial e a ausência de simulação, mas também destacam determinadas características procedimentais que possuem significância no resultado de um julgamento.

O estudo tem como limitação ter contemplado um período curto de dois anos. Resultados mais robustos poderiam ser promovidos caso se repita a análise com um número maior de anos e maior quantidade de observações (Acórdãos) em apreciação.

Dessa feita, em suma, observou-se que o CARF manteve, aparentemente, o mesmo critério de julgamento adotado anteriormente a Operação Zelotes e que há fatores não expressos nos votos que podem influenciar no resultado do julgamento. $\mathrm{O}$ ajustamento da relação jurídica tributária mediante o processo administrativo fiscal conduz a uma maior segurança jurídica, permitindo uma maior paz entre o contribuinte e o fisco. Isto posto, defensáveis estudos como esse que definam e pacifiquem essa relação, evitando lides tributárias e a crescente judicialização das atividades empresariais.

\section{Referências}

ABRAHAM, Marcus. Os 10 anos da norma geral antielisiva e as cláusulas do propósito negocial e da substância sobre a forma presentes no direito brasileiro. Revista Dialética de Direito Tributário, n. 192, p. 79-93, 2011.

ALCHOURRÓN, Carlos E.; BULYGIN, Eugenio. Introducción a la metodología de las ciencias jurídicas y sociales. Ciudad de Buenos Aires: Editorial ASTREA, 1975.

ANDRADE, Janaína Nicolau de; SANTANA, Hadassah Laís de Souza; FRANCO JÚNIOR, Nilson José. As possíveis transformações no Conselho Administrativo de Recursos Federais. Revista Jurídica, v. 04, n. 45, p.534-564, 2016.

CARVALHO, Paulo de Barros. Entre a forma e o conteúdo na desconstituição dos negócios jurídicos. Revista da Faculdade de Direito da Universidade de São Paulo. v. 105, n., p. 409-431, 2010.

CALIJURI, Mônica Sionara Schpallir. Avaliação da gestão tributária a partir de uma perspectiva multidisciplinar. São Paulo: USP, 2009.

COELHO, Luiz Felipe de Almeida. Tax Avoidance com operação de cisão, fusão e incorporação: entendendo os critérios de validade utilizados pelo CARF. 2013. 75 f. Dissertação (Mestrado em Ciências Contábeis) - Programa de Pós-graduação da Fundação Instituto Capixaba de Pesquisas em Contabilidade, Economia e Finanças(FUCAPE), Vitória, 2013.

DESEI, A. Mihir; DHARMAPALA, Dhmmika. Corporate tax avoidance and firm value. Review of Economics \& Statistics. Working Paper 11241, 2009. Disponível em: <http://www.nber.org/papers/w11241>.Acessoem: 05 mar. 2018. 
DYRENG. Scott; HANLON, Michelle; MAYDEW, L. Edward. The effects of executives on corporate tax avoidance. The Accounting Review, v. 85, n. 4, p. 1163-1189, 2010.

GRAHAM, John R.; HANLON, Michelle; SHEVLIN, Terry; SHROFF, Nemit. Incentives for tax planning and avoidance: evidence from the field. The Accounting Review, v. 89, n. 3, p. 991-1023, 2014.

GOUVEIA, Fernando Henrique Câmara; AFONSO, Luís Eduardo. Uma análise da remuneração dos sócios por meio do planejamento tributário. Revista de Administração Mackenzie, v. 14, n. 2, p.6998, 2013.

GUJARATI, Damodar N.; PORTER, Dawn C. Econometria básica. 5. ed. Porto Alegre:AMGH, 2011.

IUDÍCIBUS, Sérgio de; POHLMANN, Marcelo Coletto. Classificação interdisciplinar da pesquisa tributária. Revista de Contabilidade e Finanças da UFBA, v. 1, n.1, p. 1-18, 2007.

LARSON, Ron; FARBER, Betsy. Estatística aplicada. 4.ed. São Paulo: Pearson, 2010. 637 p.

MARTINEZ, Antônio Lopo; COELHO, Luiz Felipe de Almeida. Planejamento tributário com operações societárias: critérios de validade utilizados pelo CARF. Revista Contemporânea de Contabilidade da Universidade Federal de Santa Catarina, v. 13, n. 30, p. 193-213, 2016.

MENEZES, Alana Gemara Lopes Nunes. A boa-fé sob a ótica do CARF no planejamento tributário. Recife: Universidade Católica de Pernambuco, 2016.

MORAES, Ricardo Lopes de. O propósito negocial como elemento essencial para o planejamento tributário na era da sustentabilidade. AREEL FAAR Arquimenes, v. 02, n. 02, p.41-68, 2014.

NOBRE JÚNIOR, Edilson Pereira; PIMENTEL, João Otávio Martins. Contencioso administrativo tributário federal no Brasil: O que esperar do CARF depois da operação zelotes? Revista da Faculdade de Direito da Universidade Federal de Minas Gerais, n. 69, p. 161-182, 2016.

QUINTINO, Jessica Priscilla; MACEI, Demetrius Nichele. O propósito negocial no planejamento tributário sob a ótica do CARF. Revista Dialética de Direito, v. 17, n. 113, p. 579-604, 2015.

RANDOLPH, David W.; SEIDA, Jim A. Balancing tax and financial reporting objectives: effective tax planning within the property and casualty insurance industry. Issues in Accounting Education, v. 22, n. 2, p. 285-318, 2007.

SANTA, Silvio Luís Leite; REZENDE, Amaury José. Elisão fiscal e valor da firma: evidências do Brasil, Revista Contemporânea de Contabilidade da Universidade Federal de Santa Catarina, 114 -133, set./dez. 2016.

SCHOUERI, Luís Eduardo (coord.) Planejamento tributário e o "propósito negocial": mapeamento de decisões do conselho de contribuintes de 2002 a 2008. São Paulo: Quartier Latin, 2010. 